\title{
The Danish Multiple Sclerosis Treatment Register
}

This article was published in the following Dove Press journal:

Clinical Epidemiology

25 October 2016

Number of times this article has been viewed

\author{
Melinda Magyari ${ }^{1,3}$ \\ Nils Koch-Henriksen ${ }^{1,2}$ \\ Per Soelberg Sørensen ${ }^{3}$ \\ 'Danish Multiple Sclerosis Registry, \\ Department of Neurology, \\ Rigshospitalet, Copenhagen, \\ ${ }^{2}$ Department of Clinical Epidemiology, \\ Clinical Institute, University of Aarhus, \\ Aarhus, ${ }^{3}$ Danish Multiple Sclerosis \\ Center, Department of Neurology, \\ Rigshospitalet, University of \\ Copenhagen, Copenhagen, Denmark
}

Correspondence: Melinda Magyar Danish Multiple Sclerosis Center, Department of Neurology, Copenhagen University Hospital, Rigshospitalet

DK-2100 Copenhagen, Denmark

Tel +4521689825

Fax +4535452626

Email melinda_magyari@dadlnet.dk
Aim of the database: The Danish Multiple Sclerosis Treatment Register (DMSTR) serves as a clinical quality register, enabling the health authorities to monitor the quality of the diseasemodifying treatment, and it is an important data source for epidemiological research.

Study population: The DMSTR includes all patients with multiple sclerosis who had been treated with disease-modifying drugs since 1996. At present, more than 8,400 patients have been registered in this database. Data are continuously entered online into a central database from all sites in Denmark at start and at regular visits.

Main variables: Include age, sex, onset year and year of the diagnosis, basic clinical information, and information about treatment, side effects, and relapses.

Descriptive data: Notification is done at treatment start, and thereafter at every scheduled clinical visit 3 months after treatment start, and thereafter every 6 months. The longitudinally collected information about the disease activity and side effects made it possible to investigate the clinical efficacy and adverse events of different disease-modifying therapies.

Conclusion: The database contributed to a certain harmonization of treatment procedures in Denmark and will continue to be a major factor in terms of quality in clinical praxis, research and monitoring of adverse events, and plays an important role in research.

Keywords: multiple sclerosis, epidemiology, immunomodulatory treatment, neutralizing antibodies, observational studies, registry research, disease modifying therapy

\section{Introduction}

Multiple sclerosis (MS) is a chronic inflammatory disease of the central nervous system with a multifactorial etiology and an increasing complexity of new and more effective disease-modifying therapies (DMTs). ${ }^{1}$

The Danish Multiple Sclerosis Treatment Register (DMSTR) was established in 1996 with the introduction disease-modifying drugs (DMDs) for patients with relapsing-remitting multiple sclerosis (RRMS) within the framework of Danish Multiple Sclerosis Group (DMSG) as a nationwide scientific database, associated with the Danish Multiple Sclerosis Registry. ${ }^{2}$

The aims of the database were then to investigate the long-term effect of the first approved immunomodulatory drug, interferon (IFN)- $\beta$ in MS and to measure the effect of neutralizing antibodies (NAbs) on the efficacy of the disease-modifying treatment. ${ }^{3}$ Registration was mandatory in order for reimbursement from the administrative units, which at that time were the Danish counties. Only departments of neurology are authorized to treat with DMD. submit your manuscript | www.dovepress.com

Dovepress

http://dx.doi.org/10.2147/CLEP.S99500
Clinical Epidemiology 2016:8 549-552 (Thematic series on clinical quality databases in Denmark) 549 (c) (i) (5) 2016 Magyari et al. This work is published and licensed by Dove Medical Press Limited. The full terms of this license are available at https://www.dovepress.com/terms. C. you hereby accept the Terms. Non-commercial uses of the work are permitted without any further permission from Dove Medical Press Limited, provided the work is properly attributed. For permission for commercial use of this work, please see paragraphs 4.2 and 5 of our Terms (https://www.dovepress.com/terms.php). 
Since 1996, prospectively collected clinical data of all Danish patients have been sent to DMSTR from all Danish Departments of Neurology.

In 2006, the DMSTR changed from being a research database to a clinical quality database under the auspices of Danish counties and from 2007, Danish Regions.

The aim of the database is to monitor indicators of quality of processing immunomodulatory and immunosuppressive therapy of patients with MS with reference to standards given by the DMSG and the Danish Regions (the current administrative units and the owners of the Danish public hospitals). A by-product of the clinical quality databases is collection of data that can be used for research. Recently, data from the DMSTR have also been used by the Council for the Use of Expensive Hospital Medicines.

\section{Methods}

Before 2008, the DMSTR was notified by using paper clinical records form collected from all departments of neurology. From 2008, data are entered directly online into a central database under the Database Secretariat of the Danish Regions. The patients are informed that their clinical data are recorded in a central database, and that this is mandatory for their treatment. Therefore the DMSTR is virtually complete.

\section{Study population}

The DMSTR includes all patients with MS and clinically isolated syndrome, who have been treated with DMD since 1996. At present, more than 8,400 patients have been registered in this database. The inclusion criteria are the same as the current treatment criteria. The DMSTR also regularly exports data to the Danish Multiple Sclerosis Registry, ensuring high completeness of that register.

\section{Main variables}

Baseline information of clinical history and physical examination are entered at treatment initiation. Data include age, sex, onset year and year of the diagnosis, and basic clinical information.

Notification is done at treatment start, and thereafter at every scheduled clinical visit 3 months after treatment start, and thereafter every 6 months. Each notification includes among other variables information about side effects of medication, results of radiological, and some laboratory investigations. The indicators of quality include timely control visits and blood tests and, in patients treated with second-line DMD, timely regular magnetic resonance imaging (MR) scans.

\section{Data administration and access}

The DMSTR is administered according to the Act on Processing of Personal Data at the Danish Regions' Clinical Quality Development Program, in Aarhus. To date, the DMSTR has been financed via the governmental grant system available for national "quality registries" in Denmark. The aim of this clinical quality database is to provide predefined quality indicators to The Danish Clinical Registries, which contains information about individual patients, used for improvement of quality, research, and surveillance purposes. The program is exempt from patient consent to data collection. Research access to anonymized data does not need approval from The National Committee on Health Research Ethics. Access to nonanonymized data requires approval from the Danish Health Authority. All access to data for research purposes requires approval from the Danish Data Protection Agency. Research applications are evaluated by the DMSTR's steering committee, which represents comprehensive clinical and epidemiological expertise. Access to the database is granted by the administrative organization after evaluation of the application.

\section{Research contributions}

The DMSTR has produced a wide range of peer-reviewed scientific publications, including 17 publications during the last 15 years. The use of immunomodulatory therapies in Denmark, focusing on treatment results and side effects in a whole population of patients with RRMS, has been reported in a comprehensive article. ${ }^{4}$

A series of publications sustained the evidence regarding the dynamics and detrimental effect of NAbs against IFN- $\beta$ and acknowledged and contributed to the interpretation and general acceptance of this issue in the international scientific community. The Danish National IFN-beta Project was the largest independent study that examined the impact of NAbs on the therapeutic effect of IFN- $\beta$ in patients with RRMS. ${ }^{5}$ Several other original publications from the DMSTR clarified the clinical importance of NAbs against IFN ${ }^{6,7}$ and against natalizumab. ${ }^{8}$ This contributed to the development of international guidelines. ${ }^{9}$ A nationwide cohort study that included all treated patients with onset of MS between 2000 and 2004 reported no differences in treatment response to IFN- $\beta$ between sexes. ${ }^{10}$

Prospectively collected data in DMSRT linked to immunological biomarkers served as basis to evaluate whether or not treatment effect to IFN- $\beta$ therapy can be predicted. ${ }^{11}$

The treated MS population has been systematically followed for many years; therefore, the DMSTR provides 
a platform for the conduct of observational studies on MS "real-world" data. After natalizumab therapy became available as DMT, one of the first publications reporting disease activity in patients treated with natalizumab was based on data from DMSTR. ${ }^{12}$ Rebound of disease activity after discontinuation of natalizumab therapy in highly active MS patients has also been investigated. ${ }^{13}$ A recently submitted publication evaluates the side effects of fingolimod treatment, and a prospective cohort study is planned to characterize the long-term safety profile of DMT and determine the incidence of adverse events of special interest in a real-life setting. The long follow-up time and completeness enables a better knowledge of the treatment modified history of the disease.

\section{International collaborations}

The DMSTR is a population-based treatment registry, but for several research purposes, the number of persons included in the registry may be too few for adequate statistical power. This can apply for many aspects of observational studies, especially regarding long-term real-life effectiveness of DMT. As a consequence, the DMSTR has established collaborations to other MS registries to enable efficient pooling of data; however, there are still technical, ethical, legal, and political challenges to be faced, but hopefully these collaborations could answer questions that cannot be answered by one single database.

\section{Conclusion}

The DMSTR is internationally unique because of the consistent follow-up since 1996 and for being purely population based. The database contributed to a certain harmonization of treatment procedures in Denmark and will continue to be a major factor in terms of quality in clinical praxis, research and monitoring of adverse events, but is also an essential data source for epidemiological research. Systematic recording of data into national MS registries is needed to optimize treatment aims to facilitate research and for improved understanding of disease mechanisms and improved health care in MS.

Population-based studies combining health and social registers can optimally be carried out in Denmark, due to linkage between registers at the individual level by a unique personal identification number (civil registration-number) which is used by all national registers. In this respect, the DMSTR provides extensive research possibilities in studies of etiology and community medicine in Denmark, as well as internationally.

\section{Acknowledgments}

This paper was funded by the Program for Clinical Research Infrastructure (PROCRIN), established by the Lundbeck Foundation and the Novo Nordisk Foundation and administered by the Danish Regions.

\section{Disclosure}

MM has served on scientific advisory board for Biogen Idec and Teva Pharmaceutical Industries Ltd.; has received honoraria for lecturing from Biogen Idec, Merck Serono, Novartis, Teva Pharmaceutical Industries Ltd.; has received support for congress participation from Biogen Idec, Teva Pharmaceutical Industries Ltd., Genzyme, and Novartis. NK-H has received honoraria for lecturing and participation in advisory councils, travel expenses for attending congresses and meetings from Bayer Schering Pharma AG, Merck Serono, Biogen Idec, Teva Pharmaceutical Industries Ltd., Sanofi-Aventis, and Novartis. PSS has served on scientific advisory boards for Biogen Idec, Merck Serono, Novartis, Genzyme, Teva Pharmaceutical Industries Ltd., GlaxoSmithKline, MedDay Pharmaceuticals, and Forward Pharma; has been on steering committees or independent data monitoring boards in clinical trials sponsored by Merck Serono, Teva Pharmaceutical Industries Ltd., and GlaxoSmithKline; and has received speaker honoraria from Biogen Idec, Merck Serono, Teva Pharmaceutical Industries Ltd., Genzyme, and Novartis. His department has received research support from Biogen Idec, Bayer Schering, Merck Serono, Teva Pharmaceutical Industries Ltd., Baxter, Sanofi-Aventis, BioMS, Novartis, Bayer, RoFAR, Roche, Genzyme, from the Danish Multiple Sclerosis Society, the Danish Medical Research Council, and the European Union Sixth Framework Programme: Life sciences, Genomics and Biotechnology for health. The authors report no other conflicts of interest in this work.

\section{References}

1. Sørensen PS. New management algorithms in multiple sclerosis. Curr Opin Neurol. 2014;27:246-259.

2. Koch-Henriksen N, Magyari M, Laursen B. Registers of multiple sclerosis in Denmark. Acta Neurol Scand Suppl. 2015;132:4-10.

3. Koch-Henriksen N, Sørensen PS. The Danish National Project of interferon-beta treatment in relapsing-remitting multiple sclerosis. The Danish Multiple Sclerosis Group. Mult Scler. 2000;6:172-175.

4. Sørensen PS, Koch-Henriksen N, Ravnborg M, et al. Immunomodulatory treatment of multiple sclerosis in Denmark: a prospective nationwide survey. Mult Scler. 2006;12:253-264.

5. Sørensen PS, Ross C, Clemmesen KM, et al. Antibodies to IFNbeta: the Danish National IFN-beta Project. Neurology. 2003;61: S27-S28.

6. Sørensen PS, Ross C, Clemmesen KM, et al. Clinical importance of neutralising antibodies against interferon beta in patients with relapsingremitting multiple sclerosis. Lancet. 2003;362:1184-1191. 
7. Koch-Henriksen N, Sørensen PS, Bendtzen K, Flachs EM. The clinical effect of neutralizing antibodies against interferon-beta is independent of the type of interferon-beta used for patients with relapsing-remitting multiple sclerosis. Mult Scler. 2009;15:601-605.

8. Jensen PE, Koch-Henriksen N, Sellebjerg F, Sørensen PS. Prediction of antibody persistency from antibody titres to natalizumab. Mult Scler. 2012;18:1493-1499.

9. Sørensen PS, Deisenhammer F, Duda P, et al. Guidelines on use of anti-IFN-beta antibody measurements in multiple sclerosis: report of an EFNS Task Force on IFN-beta antibodies in multiple sclerosis. Eur J Neurol. 2005;12:817-827.

10. Magyari M, Koch-Henriksen N, Laursen B, Sørensen PS. Gender effects on treatment response to interferon-beta in multiple sclerosis. Acta Neurol Scand. 2014;130:374-379.
11. Sellebjerg F, Søndergaard HB, Koch-Henriksen N, Sørensen PS, Oturai AB. Prediction of response to interferon therapy in multiple sclerosis. Acta Neurol Scand. 2014;130:268-275.

12. Oturai AB, Koch-Henriksen N, Petersen T, Jensen PE, Sellebjerg F, Sørensen PS. Efficacy of natalizumab in multiple sclerosis patients with high disease activity: a Danish nationwide study. Eur J Neurol. 2009; 16:420-423.

13. Sørensen PS, Koch-Henriksen N, Petersen T, Ravnborg M, Oturai A, Sellebjerg F. Recurrence or rebound of clinical relapses after discontinuation of natalizumab therapy in highly active MS patients. $J$ Neurol. 2014;261:1170-1177

\section{Publish your work in this journal}

Clinical Epidemiology is an international, peer-reviewed, open access, online journal focusing on disease and drug epidemiology, identification of risk factors and screening procedures to develop optimal preventative initiatives and programs. Specific topics include: diagnosis, prognosis, treatment, screening, prevention, risk factor modification,

Submit your manuscript here: http://www.dovepress.com/clinical-epidemiology-journal

\section{Dovepress}

systematic reviews, risk \& safety of medical interventions, epidemiology \& biostatistical methods, and evaluation of guidelines, translational medicine, health policies \& economic evaluations. The manuscript management system is completely online and includes a very quick and fair peer-review system, which is all easy to use. 